\title{
O ensino do atletismo nas aulas de educação física
}

A atletismo é considerado o esporte base para todas as modalidades esportivas, pois advém da execução dos movimentos naturais do homem nas suas mais diversas provas. Sabendo que a escola, especificamente nas aulas de educação física, a criança pode oportunizar através da pratica do atletismo o desenvolvimento dos aspectos físicos, motores, cognitivos e afetivos. O presente trabalho tem como objetivo identificar a incidência das principais modalidades do atletismo trabalhadas das aulas de Educação Física da rede pública de ensino de Bodocó/PE. Esse estudo trata de uma pesquisa de caráter quantitativa-descritiva, de campo, com corte transversal. A amostra foi composta por 14 professores da rede pública de ensino da cidade de Bodocó/Pernambuco. Foi utilizado um questionário semiestruturado proposto pelo pesquisador, visando identificar natureza do local da prática, horários de desenvolvimentos da prática do atletismo, predominância de sexo na prática do atletismo na escola e a incidência das provas de corridas, saltos, arremessos/lançamentos desenvolvidas nas práticas educativas. A análise de dados foi mensurada através de estatística descritiva por distribuição de frequência que usou as variáveis estatísticas, através do software SPSS na sua versão 23. Os resultados apontam uma predominância do sexo masculino nas práticas do atletismo, o campo como local predominante de pratica, o atletismo demostrou se praticado em ambos os turnos escolares. As corridas rasas $(92,9 \%)$, os saltos em distância $(42,9)$ e em altura $(57,1 \%)$, arremesso do peso $(35,7 \%)$, lançamento do disco $(35,7 \%)$, lançamento do dardo (28,6\%), tiveram maior incidência. Conclui-se que a prática do atletismo escolar da rede pública da cidade de Bodocó/PE é evidenciada em sua maior proporção dentro das provas de campo.

Palavras-chave: Esporte; Prática esportiva; Educação Física.

\section{Athletics teaching in physical education classes}

Athletics is considered the base sport for all sports, as it comes from the execution of natural movements of man in his most diverse competitions. Knowing that the school, specifically in physical education classes, the child can make the development of physical, motor, cognitive and affective aspects possible through the practice of athletics. This work aims to identify the incidence of the main modalities of athletics worked in the Physical Education classes of the public school system in Bodocó-PE. This study is a quantitative-descriptive, field-based, cross-sectional research. The sample consisted of 14 public school teachers in the city of BodocóPernambuco. A semi-structured questionnaire proposed by the researcher was used, aiming to identify the nature of the practice site, times of development of the practice of athletics, predominance of sex in the practice of athletics at school and the incidence of running, jumping, throwing/launching tests developed in the practices educational. The data analysis was measured through descriptive statistics by frequency distribution that used the statistical variables, using the SPSS software in its version 23 . The results indicate a predominance of males in athletics practices, the field as the predominant place of practice, athletics has been shown to be practiced in both school shifts. Shallow runs (92.9\%), long jumps (42.9) and high (57.1\%), shot put (35.7\%), discus (35.7\%), throw dart (28.6\%), had a higher incidence. It is concluded that the practice of school athletics in the public school in the city of Bodocó-PE is evidenced in its greatest proportion within the field tests.

Keywords: Keyword; Keyword; Keyword.

Topic: Práticas Esportivas e de Lazer

Reviewed anonymously in the process of blind peer.
Received: 12/03/2020

Approved: 08/05/2020
Marcos Antonio Araujo Bezerra (iD)

Centro Universitário Dr. Leão Sampaio, Brasil

http://lattes.cnpq.br/4643352879633283

http://orcid.org/0000-0002-3385-4024

marcosantonio@leaosampaio.edu.br

Elton Carlos Bezerra Horas

Centro Universitário Dr. Leão Sampaio, Brasil

eltonhoras@gmail.com

Gabriela Gomes de Oliveira Bezerra

Centro Universitário Dr. Leão Sampaio, Brasil

http://lattes.cnpq.br/6330341118187369

gabriela.o.bezerra@gmail.com

\author{
Cícero Idelvan de Morais \\ Centro Universitário Dr. Leão Sampaio, Brasil \\ http://lattes.cnpq.br/9480395648727651 \\ idelvan@leaosampaio.edu.br \\ Cícero Rodrigo da Silva (it \\ Centro Universitário Dr. Leão Sampaio, Brasil \\ http://lattes.cnpq.br/8286964349591404 \\ http://orcid.org/0000-0003-4655-7982 \\ rodrigo@leaosampaio.edu.br \\ Cícero Cleber Brito Pereira (iD \\ Centro Universitário Dr. Leão Sampaio, Brasil \\ http://lattes.cnpq.br/6554764959422181 \\ http://orcid.org/0000-0002-9402-9810 \\ cicerocleber@univs.edu.br
}

Referencing this:

BEZERRA, M. A. A.; HORAS, E. C. B.; BERREZA, G. G. O.; MORAIS, C. I.; SILVA, C. R.; PEREIRA, C. C. B.. O ensino do atletismo nas aulas de educação física. Educationis, v.8, n.2, p.36-40, 2020. DOI: http://doi.org/10.6008/CBPC2318-3047.2020.002.0005 


\section{INTRODUÇÃO}

O atletismo é um esporte clássico e por usar movimentos naturais ele se torna de extrema importância para ser trabalhado nas aulas de Educação Física. Pois, ajudará no desenvolvimento: motor, psicológico, social dos alunos que o praticam, servindo também como base para o desenvolvimento de outros esportes que é trabalhado no âmbito escolar.

Para Gomes (2008) é importante reconhecer o desenvolvimento do atletismo como um instrumento pedagógico e de formação, de indivíduos com o objetivo de possibilitar aos praticantes de atletismo o conhecimento sobre as suas provas básicas, estimulando a realização de práticas e hábitos de vida saudáveis como as atividades motoras, levando ao aprendizado das normas, a busca de lugares e implementos para a sua prática, á vivencia em grupos que buscam os mesmos objetivos, um contato de forma equilibrada e a compreensão de suas vantagens para saúde física, mental e social do indivíduo.

Bragada (2000), afirma que o conteúdo Atletismo, no âmbito escolar, pode servir como uma referência essencial, pois as suas aptidões e habilidades serão desenvolvidas na realização da prática no decorrer das aulas, servindo de suporte a uma série de esportes. É de considerável importância se praticar atividades esportivas para adquirir um repertorio motor, desenvolver o intelecto e estimular a socialização das crianças. Dessa forma eles agregaram cada vez mais habilidades especificas do atletismo (NERES, 2014).

Para Castro et al. (2012), o atletismo mesmo sendo praticado em sua maioria por provas individuais, ainda promove o alargamento das relações pessoais entre os praticantes, buscando com que eles passem a colaborar e ser mais independentes para que consigam chegar à os objetivos oferecidos, dessa forma adaptando às aulas que serão realizadas, e organizem para ser feitas em conjunto.

Matthiesen et al. (2014) ressaltam em sua pesquisa que apesar de ser um dos esportes mais tradicionais no campo esportivo, o atletismo no Brasil constata pela sua história que existem, marcas do menosprezo/omissão das escolas em relação a sua maneira de ensino e a sua propagação como movimento cultural da sociedade. Chegado à conclusão, que no Brasil se vê uma instrução do atletismo marcada pela ausência de coordenação em sua construção, refletindo numa formação sem aprofundamentos.

Marques et al. (2009) reforçam em seu trabalho dizendo que existe, uma transferência limitada de movimento e jogos, deixando cada vez mais limitado por causa da falta de lugares específicos e equipamentos básicos, estimulo imaginação dos educadores e, por falta de instrução continuada, que ajudaria a trazer novas maneiras de incrementar as aulas. Com isso a Educação Física escolar não tem se importado em buscar soluções trazendo novidades que consigam contribuir para encontra uma maior diversidade de brincadeiras e atividade estimuladoras e trazendo uma maior variedade de movimentos.

Para Castro et al. (2012), o atletismo é uma disciplina clássica da Educação Física e ainda vem sendo negligenciada. A sua prática segui sem ser desenvolvida no âmbito escolar dessa forma faz o esporte gradativamente ser deixada para traz. Havendo uma necessidade de encontrar novas formas metodológicas para que o conteúdo seja mais valorizado na comunidade e dentro do contexto escolar. Cada educador deve buscar inovações trazendo soluções metodológicas de lecionar. Fazendo com que suas aulas atendam os 
anseios de seus alunos, dando mais motivações a os mesmos. O presente trabalho tem como objetivo identificar a incidência das principais modalidades do atletismo trabalhadas das aulas de Educação Física da rede pública de ensino de Bodocó/PE.

\section{MATERIAIS E MÉTODOS}

Esse estudo se trata de uma pesquisa de caráter quantitativa-descritiva, de campo, com corte transversal. A amostra foi composta por 14 professores da rede pública de ensino da cidade de Bodocó/Pernambuco, adotou-se como critérios de inclusão professores efetivos da rede pública municipal e estadual, formação especifica em licenciatura em educação física, foram excluídos os professores que não estivessem desenvolvendo suas atividades acadêmicas em sala de aula.

Foi utilizado um questionário semiestruturado proposto pelo pesquisador, visando identificar natureza do local da prática, horários de desenvolvimentos da prática do atletismo, predominância de sexo na prática do atletismo na escola e a incidência das provas de corridas, saltos, arremessos/lançamentos desenvolvidas nas práticas educativas.

O estudo utilizou o termo de consentimento livre e esclarecido (TCLE), e da resolução 466/12 do conselho nacional de saúde do ministério da saúde. O período de coleta transcorreu entre Março e Maio de 2019. E a análise de dados foi mensurada através de estatística descritiva por distribuição de frequência que usou as variáveis estatísticas, através do software SPSS na sua versão 23.

\section{RESULTADOS E DISCUSSÃO}

Participaram da presente pesquisa, 14 professores, da rede municipal de ensino (71,4\%) e da rede estadual $(28,6)$, onde $50 \%$ tem especialização e outros $50 \%$ apenas a graduação em educação física.

Tabela 1: Características da prática do atletismo escola nas escolas públicas de Bodocó/PE.

\begin{tabular}{|c|c|}
\hline Natureza do local da prática & $(\%)$ \\
\hline Quadra & 7,1 \\
\hline Campo & 92,9 \\
\hline \multicolumn{2}{|c|}{ Horários de desenvolvimentos da prática do atletismo } \\
\hline Turno escolar regular & 14,3 \\
\hline Contra turno escolar & 50 \\
\hline Ambos os turnos & 35,7 \\
\hline \multicolumn{2}{|c|}{ Predominância de sexo na prática do atletismo na escola } \\
\hline Masculino & 92,9 \\
\hline Feminino & 7,1 \\
\hline \multicolumn{2}{|c|}{ Incidência das provas de corridas desenvolvidas nas práticas educativas } \\
\hline Corridas rasas & 92,9 \\
\hline Corridas com barreiras & 7,1 \\
\hline \multicolumn{2}{|c|}{ Incidência das provas de saltos desenvolvidas nas práticas educativas } \\
\hline Salto em Distancia & 42,9 \\
\hline Salto em altura & 57,1 \\
\hline \multicolumn{2}{|c|}{ Incidência das provas de arremessos/lançamentos desenvolvidas nas práticas educativas } \\
\hline Arremesso do peso & 35,7 \\
\hline Lançamento do Disco & 35,7 \\
\hline Lançamento do Dardo & 28,6 \\
\hline
\end{tabular}

Observa-se na tabela 1 que 7,1\% dos professores trabalham a modalidade em quadra esportiva, Goveia et al. (2014) mostram em seu estudo que a quadra e o pátio da escola ficam à disposição para a prática do atletismo. Por outro lado, as escolas brasileiras em sua grande maioria não têm um espaço para o 
desenvolvimento das provas de campo e fundo a escola dificultando a realização dessas provas. Noll et al. (2008) reforça em seu trabalho mostrando que a maioria das escolas pesquisadas tem um bom espaço para o desenvolvimento do atletismo. Onde se encontra quadra, campo, e diversos materiais oficiais para diversas modalidades do atletismo

Quando questionados sobre a predominância do sexo durante a pratica do atletismo na escola. Verificou-se que 92,9\% apresentam apenas meninos em sua prática, Ribeiro et al. (2014) também encontra diferença de sexo no seu trabalho constatando que o percentual de meninos praticantes de modalidades esportivas é $92,3 \%$, e que o percentual de meninas praticantes de modalidades esportivas é de $78,6 \%$. Já Guerra et al. (2011) em sua pesquisa: a preferência esportiva em escolares de ambos os sexos. Encontra um resultado oposto onde foram pesquisados escolares das regiões norte, sul, leste, oeste, centro contatou que a preferência do sexo feminino em relação ao atletismo é maior em quatro das cinco regiões pesquisadas.

Quanto a incidência da pratica Goveia et al. (2014) também constatam que os alunos praticantes do atletismo preferem as corridas de velocidade nas aulas de atletismo. Onde foi encontrado o resultado que $(46,15 \%)$ dos alunos que praticam o atletismo optam pelas corridas de velocidade. Já Lohmann (2011) define a corrida com barreira dizendo que é uma prova que consiste em fazer um determinado percurso da pista com 10 barreiras dispostas sobre a pista. Que devem ser transpassadas durante a realização da prova. E devido à utilização de materiais específicos torna a pratica mais difícil dentro da escola.

Bonfim (2011) em seu trabalho encontra um resultado diferente, que traz o questionamento a professores do município de Boa Vista/RR. Perguntando quais as modalidades do atletismo mais trabalhadas, onde $18,63 \%$ professores relatam trabalhar o salto em distância e $(4,5 \%)$ professores trabalham o salto em altura. Brito et al. (2004) traz em sua pesquisa que foi realizada com 132 atletas ranqueados da categoria infantil, mostrando que $72 \%$ praticam saltos verticais e $88 \%$ praticam os saltos horizontais. Também encontrando um resultado aposto a pesquisa. Bonfim (2011) encontra um resultado oposto no seu estudo, onde questiona as modalidades mais apreciadas pelos alunos, sob o ponto de vista dos professores. Encontrou o resultado em que $(9,72 \%)$ professores apontaram que os alunos praticam do arremesso do peso e $(1,62 \%)$ professores apontam que alunos praticam o lançamento do disco. Santos (2016) corrobora em seu trabalho, em que questionou treinadores do Rio Grande Do Norte que trabalham com projetos e trabalhos voluntários em escolas, sobre quais provas eles trabalhavam nos treinos. Identificando que 15\% dos professores trabalham os lançamentos em suas aulas.

\section{CONCLUSÕES}

Conclui-se que a prática do atletismo escolar da rede pública da cidade de Bodocó/PE é evidenciada em sua maior proporção dentro das provas de campo, ressalta-se ainda a ausência da prática das provas de Marcha atlética e Cross country. Evidencia-se a importância desse esporte por ser um esporte base para outras modalidades e para o desenvolvimento de seus praticantes sendo um esporte inclusivo e socializador, fato esse desafiante dentro do ambiente escolar. Recomenda-se que a temática de atletismo seja melhor estruturada dentro do ambiente escolar, visando oportunizar ao aluno a possibilidade de desenvolvimento 
de capacidades físicas, emocionais e cognitivas, bem como novas pesquisas dentro desse eixo temático.

\section{REFERÊNCIAS}

BRITO, N.; FONSECA, A.; ROLIM, R.. Os melhores atletas nos escalões de formação serão igualmente os melhores atletas no escalão sénior? Análise centrada nos rankings femininos das diferentes disciplinas do Atletismo ao longo das últimas duas décadas em Portugal. Revista Portuguesa de Ciências do Desporto, v.4, n.1, p.17-28, 2004.

BRAGADA, J.. Atletismo na escola: proposta programática para abordagem dos lançamentos 'leves'. Horizonte-Revista de Educação Física e Desporto, Bragança, v.17, n.99, 2000.

BONFIM, A. B. C.. O atletismo como conteúdo para a Educação física Escolar: um olhar docente no município de Boa Vista/RR. EFDeportes, Buenos Aires, n.152, 2011.

CASTRO, M. M.; BANDEIRA, R. A.. O Ensino Do Atletismo Como Conteúdo Pedagógico. Cáceres: UNEMAT, 2012.

GOVEIA, J. C.; VARGAS, L. M.. Atletismo se aprende na escola: possibilidades pedagógicas e metodologias de ensino da modalidade para crianças de 11 a 12 anos. Revista Eletrônica Fafit/Facic, v.5, n.2, 2014.

GOMES, C. L. J.. O atletismo como conteúdo pedagógico e formativo. Londrina, 2008.

GUERRA, S. N.; SILVA, V. O.; LEÃO FILHO, I. B.; FREITAS, M. R.. Preferência esportiva em escolares de ambos os sexos no município de São José dos Campos. In: ENCONTRO LATINO AMERICANO DE INICIAÇÃO CIENTÍFICA, 15; ENCONTRO LATINO AMERICANO DE PÓS-GRADUAÇÃO, 11. Anais. João Pessoa: Universidade do Vale do Paraíba, 2011.
LOHMANN, L. A.. Atletismo: manual técnico para atletas iniciantes. Rio De Janeiro: Sprint, 2011.

MATTHIESEN, S. Q.. Corridas: Atletismo I. São Paulo: Odysseus Editora, 2014.

MARQUES, C. L.; IORA, J. A.. Atletismo escolar: possibilidades e estratégias de objetivo, conteúdo e método em aulas de educação física. Movimento (ESEFID/UFRGS), Porto Alegre, v.15, n.2, p.103-118, 2009.

NOLL, M.; SUÑÉ, F.; OPPERMANN, R.. O desenvolvimento do atletismo nas escolas de Teutônia/RS: um estudo exploratório. EFDeportes, Buenos Aires, n.121, 2008.

NERES, A. S.. A prática do atletismo como fator de desenvolvimento das habilidades motoras. Monografia (Especialização) - Universidade Tecnológica do Paraná, Medianeira, 2014.

RIBEIRO, J. A. B.; CAVALLI, A. S.; CAVALLI, M. O.. Nível e importância atribuídos à prática de atividade física por estudantes do ensino fundamental de uma escola pública de Pelotas/RS. Revista Mackenzie de Educação Física e Esporte, v.12, n.2, 2014.

SANTOS, F. G.. Perfil do atletismo escolar do Rio Grande do Norte: iniciação multilateral e especialização precoce. Monografia (Bacharelado) - Universidade Federal do Rio Grande do Norte, Natal, 2016. 